\title{
Tecnologias digitais na Educação Infantil: Projeto de aprendizagem com Google Maps e Google Street
}

\section{Digital technologies in Child Education: Learning project with Google Maps and Google Street View}

Tatiane Vidal dos Reis

Universidade do Vale do Rio do Sinos

Ederson Luiz Locatelli Universidade do Vale do Rio do Sinos

Eliane Soares da Silva Universidade do Vale do Rio do Sinos

Lisandra Glória Luz Camboim Universidade do Vale do Rio do Sinos

Luciane Pires Barcelos Universidade do Vale do Rio do Sinos

Josme Fortes Universidade do Vale do Rio do Sinos

\section{Ester Elisete Palmeiro Paiva}

Universidade do Vale do Rio do Sinos

\begin{abstract}
Resumo: O objetivo deste trabalho é apresentar um projeto de aprendizagem e suas atividades, realizadas a partir dos questionamentos das crianças e de uma reflexão sobre como as tecnologias digitais podem contribuir para a pesquisa e a construção do conhecimento no contexto da Educação Infantil. O projeto foi realizado com uma turma de faixa etária três de uma escola pública de Educação Infantil de um município do interior do Rio Grande do Sul. De natureza aplicada, a investigação configurou-se como pesquisa exploratória e, no que concerne a procedimentos técnicos, foi classificada como estudo de caso. Para a realização das atividades, foram utilizadas as tecnologias Google Maps e Google Street View. Com base nas reflexões teóricas, foi possível repensar a prática pedagógica junto a uma turma de Educação Infantil, bem como o uso das tecnologias digitais no contexto escolar.
\end{abstract}

Palavras-chave: Educação Infantil. Projeto de aprendizagem. Tecnologias digitais. 


\begin{abstract}
This paper aims to present a learning project and its activities, based on children's questions and a reflection on how Digital Technologies can contribute to research and knowledge construction in the context of early childhood education. The project was carried out with a group of three age group from a public school of Early Childhood Education from a town in the interior of Rio Grande do Sul. As an applied nature, the research was configured as exploratory research and, as far as technical procedures are concerned, was classified as a case study. To perform the activities, we used the technologies Google Maps and Google Street View. Based on the theoretical reflections, it was possible to rethink the pedagogical practice in a kindergarten class, as well as the use of digital technologies in the school context.
\end{abstract}

Keywords: Child Education. Learning project. Digital Technologies.

REIS, TATIANE VIDAL DOS; LOCATELLI, EDERSON LUIZ; SILVA, ELIANE SOARES DA; CAMBOIM, LISANDRA GLÓRIA LUZ; BARCELOS, LUCIANE PIRES; FORTES, JOSME; PAIVA, ESTER ELISETE PALMEIRO. Estratégias didático-metodológicas para o uso de software educativos gratuitos na educação matemática. Informática na Educação: teoria \& prática, Porto Alegre, v. 22, n. 2, p. 125-142, maio/ago. 2019

\title{
1 Introdução
}

Quando provocadas, pela Atividade Acadêmica Ensino e Aprendizagem no Mundo Digital ${ }^{1}$, a realizarmos um projeto de aprendizagem que contemplasse o uso das tecnologias digitais, nossa primeira reação foi de rejeição e negação. Rejeição, pois, quando pensávamos na realidade das nossas escolas públicas, não víamos possibilidades de acesso das crianças a alguma tecnologia digital disponível na escola, negando, assim, qualquer possibilidade de repensar nossa prática pedagógica, levando-as em consideração.

Tínhamos consciência de que a maioria das crianças, junto às famílias, possuía algum contato com as tecnologias digitais, especialmente por meio de celulares e tablets, para assistirem desenhos, filmes e também para o acesso a jogos; mas não vislumbrávamos possibilidades de utilizá-las no espaço da escola. Isso se dava devido ao fato de que nossas escolas possuíam acesso precário à internet e de que não havia computadores disponíveis para o acesso das crianças. Porém, as reflexões teóricas provocadas por diferentes leituras e as intervenções dos professores nos possibilitaram um outro olhar em relação às tecnologias digitais no espaço da escola, mais especificamente, no contexto da Educação Infantil.

Assim, surgiu o projeto "Onde é a casinha dele?", a partir de um momento de brincadeira entre as crianças no pátio da escola. Ao brincarem perto de um pedaço de tronco de árvore, algumas crianças perceberam que ali havia um "cabeludo" (nome popularmente utilizado para designar uma taturana). Diante do pequeno animal, pararam então o que estavam fazendo e iniciaram uma observação detalhada daquilo que Ihes chamou tamanha atenção. Mediante tal situação curiosa, mais crianças se aproximaram para observar e, durante o tempo em que permaneceram observando o "cabeludo" se movimentar, muitas perguntas foram surgindo, desencadeando uma conversa entre os colegas, principalmente sobre o local para onde ele estaria indo. Pela observação, pelas perguntas e conversas, chegaram à conclusão de que ele estava indo para a "casinha dele"; e, com isso, um novo questionamento surgiu: "onde é a casinha dele?".

\footnotetext{
${ }^{1}$ Atividade Acadêmica significa disciplina e faz parte do currículo da Licenciatura em Pedagogia - PARFOR.
} 
Esse momento foi registrado pela câmera do celular da professora e apresentado para as crianças em outro momento. Por isso, a pergunta "onde é a casa dele?" tornou-se o ponto de partida das investigações que proporcionaram a estruturação do projeto de aprendizagem. Dessa forma, o objetivo deste artigo é relatar as atividades realizadas a partir dos questionamentos das crianças e de uma reflexão sobre como as tecnologias digitais podem contribuir para a pesquisa e a construção do conhecimento no contexto da Educação Infantil. Considerando esse objetivo, o trabalho está estruturado da seguinte forma: na seção 2, apresentamos alguns conceitos que embasam nossa concepção sobre esse nível de ensino, assim como nossa compreensão sobre as tecnologias digitais e sua relação com o espaço escolar. Em seguida, explicitamos a metodologia utilizada para a realização do projeto de aprendizagem, intitulado "Onde é a casinha dele?". Na sequência, apresentamos o contexto em que o projeto de aprendizagem foi realizado, assim como os participantes da pesquisa. Compartilhamos então as atividades realizadas em cada etapa do projeto, que compreenderam: o início das investigações; o primeiro contato com as fotos das casas e a construção com blocos de madeira; as possibilidades de transcender o espaço da escola através do Google Maps e do Google Street View; a atividade de ligar as imagens das casas e sua localização no Google Maps; e a etapa em que as crianças puderam compartilhar suas descobertas. Para finalizar, apresentamos nossas considerações sobre a realização deste projeto, discutindo algumas das implicações da adoção das tecnologias digitais na Educação Infantil.

\section{Tecnologias digitais na Educação Infantil: descoberta e aprendizagem}

Nosso olhar para a criança da Educação Infantil se dá a partir da definição apresentada nas Diretrizes Curriculares Nacionais da Educação Infantil (DCNEI, Resolução CNE/CEB no 5/2009), em que a criança é concebida como um sujeito histórico e de direitos, que constrói sua identidade pessoal e coletiva a partir das interações, das relações e das práticas cotidianas que vivencia. Portanto, as brincadeiras e as interações permitem que as crianças estabeleçam relações, levantem hipóteses, questionem fatos e acontecimentos, construindo significados sobre si, os outros e o mundo, atuando como protagonistas no processo de construção do conhecimento. Dessa forma, a Educação Infantil desempenha um importante papel, pois tem por objetivo a ampliação do universo de experiências, conhecimentos e habilidades das crianças a fim de diversificar e consolidar novas aprendizagens (BRASIL, 2018, p. 34).

Assim, respeitar a criança como protagonista no processo de ensino e aprendizagem significa considerar suas curiosidades e questionamentos. Não basta desejar ampliar o universo de experiências, conhecimentos e habilidades das crianças, sem que se considerem as curiosidades e os questionamentos que Ihes movem, pois, de acordo com Fagundes,

Se o ser humano deixa de ser uma criança perguntadora, curiosa, inventiva, confiante em sua capacidade de pensar, entusiasmado por explorações e por descobertas, persistente nas suas buscas de soluções, é porque nós, que o educamos, decidimos "domesticar" essa criança, em vez de ajudá-la a aprender, a continuar aprendendo e descobrindo. (FAGUNDES, 1999, p. 18). 
Fagundes nos aponta a importância dos questionamentos que as crianças levantam e do quanto o papel do professor influenciará, de forma positiva ou não, para que elas não percam a capacidade de questionar. Nesse sentido, Almeida (2005), ao utilizar a metáfora da rede, escreve sobre a construção do conhecimento, a qual acontece a partir das relações e interações estabelecidas entre as pessoas com o meio e com os demais. Dessa forma, a autora afirma que estabelecer "redes de conhecimento na escola significa assumir a ótica da interação e da colaboração entre alunos, professores, funcionários, dirigentes, especialistas e comunidade. Nessa perspectiva, o professor trabalha junto com os alunos e os incentiva a colaborarem entre si, [...]". (ALMEIDA, 2005, p. 72). Assim, ainda que o processo de aprendizagem seja uma construção que passa pela individualidade de cada criança, cabe ao professor criar condições para que ela possa desenvolver-se como protagonista nesse processo; e, para isso, é necessário que o docente também esteja aberto a novos conhecimentos.

Cada vez mais, pesquisadores e formuladores de políticas educacionais sugerem que as tecnologias digitais sejam inseridas no contexto da Educação Básica, podendo contribuir para o processo de ensino e de aprendizagem das crianças. Elas não devem ser somente utilizadas como uma forma de pesquisa, mas também como meio para promoção do conhecimento e ampliação do repertório - tanto das crianças como de nós, professores -, pois, como afirma Schlemmer,

As TDs por si só não se constituem em inovações, na medida em que a inovação
implica o rompimento de paradigmas e surge no conhecer, portanto no viver e
conviver. No entanto, elas representam uma possibilidade efetiva para o
surgimento de novas compreensões com relação a conceitos como: tempo,
espaço, presença, distância, interação, informação, conhecimento, provocando
processos de desequilíbrio no sistema de significação do sujeito, impulsionando
o rompimento de paradigmas e modificando a forma de desenvolver
determinados processos. (SCHLEMMER, 2006, p. 38-39).

Assim como nossos alunos, nós, professores, estamos em constante aprendizado. A cada instante, somos confrontados com o surgimento do novo, cabendo a nós o dever de acompanharmos as inovações que essa sociedade imersa nas tecnologias nos apresenta. Além disso, as crianças estão em constante contato com as diversas tecnologias digitais em seu dia a dia; e, como nos aponta Schlemmer, precisamos estar abertos ao aprendizado que tais recursos nos proporcionam e compreender o quanto eles podem qualificar os processos de ensino e aprendizagem. Neste sentido, é necessário abandonar a ideia de que as tecnologias digitais não fazem parte do cotidiano da escola de Educação Infantil, ou de que elas apenas seriam "ferramentas" voltadas a um único objetivo, que seria o de auxiliar na pesquisa sobre determinados assuntos. De acordo com Di Felice (2012a, p. 13),

[...] uma nova cultura tecnológica e comunicativa marca o cotidiano e a existência das novas gerações que vivem em contextos sociais e midiáticos digitais, e que produzem alterações qualitativas na política, na democracia e na forma de pensar a sociedade.

Desse modo, interrogamos: como as práticas pedagógicas na Educação Infantil podem ser ressignificadas, considerando as tecnologias digitais e os estudantes deste tempo histórico e social? Nesse contexto, segundo Di Felice,

[...] não somente uma nova forma de interação, consequência de uma inovação tecnológica que altera o modo de comunicar e seus significados, mas também 
os pressupostos e as características de uma nova arquitetura social que estimula inéditas práticas interativas entre nós e as tecnologias de informação. (DI FELICE, 2012a, p. 16).

Com isso, práticas pedagógicas que levam em conta as tecnologias digitais no seu planejamento e desenvolvimento devem considerar também a interação para além da tradicional prática analógica, pois essa nova cultura tecnológica proporciona, conforme Di Felice (2012a), uma imersão que, baseada num ecossistema, estabelece uma interação constante e contínua entre sujeitos e o contexto em que habitam. Por isso,

\begin{abstract}
Não podemos mais pensar as mídias como "ferramentas", instrumentos a serem utilizados, pois, ao utilizarmos novos meios, passamos a desenvolver novos tipos de interação e experimentamos novas formas de interação social. Desde as redes sociais digitais (social network) aos celulares, as tecnologias midiáticas são portadoras de inovação não apenas no âmbito tecnológico, comunicativo e sensorial, mas também no âmbito mais amplo do social, alcançando seus diversos níveis, político, econômico, organizativo, cultural, etc. (DI FELICE, 2012a, p. 16).
\end{abstract}

Sendo assim, ao longo da realização deste projeto de aprendizagem, alguns questionamentos foram constantes: por exemplo, ele contribuiria para que repensássemos nossas práticas como docentes, especialmente no que diz respeito ao uso das tecnologias digitais? Além disso, como se daria o processo de realização do projeto que tivesse a criança como protagonista, como aquela que, a partir dos seus questionamentos, foi direcionando o nosso fazer pedagógico e o processo de ensino e aprendizagem? Nesse âmbito, segundo Schlemmer,

\begin{abstract}
A distância, assim como a presença, no processo de ensino e de aprendizagem, deveriam estar relacionadas com a interação; no entanto, sabemos que muitas vezes professores e alunos compartilham o mesmo espaço geográfico, estão fisicamente presentes, porém estão distantes, não se fazem presentes; os espaços para o diálogo, para as discussões, para que todos possam se expressar é muito pequeno, há pouco tempo para a interação, para as trocas, para o compartilhamento de idéias e experiências, o que faz com que mesmo estando próximos geograficamente e fisicamente presentes, estejamos distantes e ausentes do processo de aprendizagem, a qual tem seu ponto de partida nas suas dúvidas, necessidades, interesses. Assim, corremos o risco de ficar somente no nível da informação e não do conhecimento, pois falta interação, falta "proximidade" falta "presença". (SCHLEMMER, 2006, p. 42).
\end{abstract}

A partir da citação de Schlemmer, alguns aspectos podem ser considerados de forma alinhada ao projeto desenvolvido, tais como a presença, a ressignificação do espaço de aprendizagem, a relação com as famílias, a distância etc. Importante notar que, ao mesmo tempo em que as crianças estavam geográfica e fisicamente em sala de aula, o projeto possibilitou transcender esse espaço, remetendo-as às suas casas, situadas em diferentes lugares no bairro. Além disso, a interação entre família e escola se deu por meio da tecnologia, com o envio de fotos de suas casas para contribuir com o projeto em desenvolvimento.

Conforme a citação de Schlemmer (2015), o termo "híbrido" fundamenta-se na concepção de Bruno Latour, "que considera a conexão dos elementos das mais diversas naturezas". Segundo Schlemmer (2015), fundamentada em Latour, por híbrido

[...] se entende a mistura entre diferentes elementos, que resultam num novo elemento composto dos anteriores. [...] o híbrido é compreendido a partir de Latour (1994) enquanto constituído por múltiplas matrizes, por misturas de natureza e cultura, portanto, não comporta a separação entre cultura/natureza, 
humano/não humano etc. Híbridas são as ações e interações entre atores humanos e não humanos, em espaços e culturas analógicas e digitais, constituindo-se em fenômenos indissociáveis, redes que interligam naturezas, técnicas e culturas. Para o autor, enquanto não superarmos a distinção cultura/natureza, humano/não humano, ou seja, enquanto mantivermos a distinção ontológica, nossas atividades serão uma contínua construção de problemas e situações interpretadas como possuindo natureza científica, política,

social, econômica, ideológica etc., ou seja, uma visão de mundo compartimentada, dicotômica e excludente.

Complementando o conceito de hibridismo, tendo em vista a perspectiva de Latour (2013) e Schlemmer (2015), algumas dimensões devem ser pensadas:

I. Quanto ao espaço - ações e interações entre atores humanos e não humanos em espaços geográficos e digitais;

II. Quanto à presença - ações e interações entre atores humanos e não humanos pelas presenças física e digital virtual;

III. Quanto às tecnologias - por meio de tecnologias analógicas e digitais;

IV. Quanto às culturas - imbricamento de diferentes culturas (digitais e pré-digitais).

Por isso, sem a interação, sem a escuta atenta do professor quanto aos questionamentos das crianças, sem um olhar que promova possibilidades de descobertas, sua mera frequência à escola não será suficiente para que a criança construa conhecimentos e seja protagonista no processo de ensino e aprendizagem. Sendo assim, de acordo com Almeida, "redefine-se o papel do professor" (ALMEIDA, 2005, p. 72), em que:

O professor que associa a TIC aos métodos ativos de aprendizagem desenvolve
a habilidade técnica relacionada ao domínio da tecnologia e, sobretudo, articula
esse domínio com a prática pedagógica e com as teorias educacionais que o
auxiliem a refletir sobre a própria prática e a transformá-la, visando explorar as
potencialidades pedagógicas da TIC em relação à aprendizagem e à consequente
constituição de redes de conhecimentos.

Nesse sentido, nós, professores, a cada instante, somos confrontados com o surgimento de novas tecnologias e inovações; e é necessário que as acompanhemos, pois, assim como nós, as crianças também estão em constante contato com as diversas tecnologias digitais em seu dia a dia. Dessa forma, entendemos que tais recursos podem contribuir para o processo de ensino e aprendizagem, não apenas servindo como um meio de pesquisa, mas também contribuindo para a construção do conhecimento e a ampliação do repertório tanto das crianças como dos professores. Portanto, como nos aponta Schlemmer (2006), precisamos estar abertos ao aprendizado que as tecnologias digitais podem nos proporcionar e à investigação do modo como podem ser utilizadas nos processos de ensino e aprendizagem, considerando que elas podem fazer parte do cotidiano das escolas de Educação Infantil.

\section{Metodologia: classificação e etapas da pesquisa}

Após a fundamentação teórica, esta seção descreve o percurso metodológico, que tem por objetivo refletir e buscar respostas para as questões aqui abordadas. Para Minayo (2007, p. 14), 
a metodologia é o caminho do pensamento e a prática exercida na abordagem da realidade. Seguindo esse raciocínio, o pesquisador torna-se um sujeito atento à realidade, na qual busca cada vez mais fundamentos para sustentar o seu posicionamento em relação a ela.

Com o intuito de ir clarificando o percurso a ser adotado, do ponto de vista da abordagem, a pesquisa se caracteriza como qualitativa, pois trabalha mais com a subjetividade, é flexível, é processual, descobre, produz os dados, contrapondo-se à abordagem quantitativa. Para Silva e Menezes (2001, p. 20), a abordagem qualitativa

[...] considera que há uma relação dinâmica entre o mundo real e o sujeito, isto é, um vínculo indissociável entre o mundo objetivo e a subjetividade do sujeito que não pode ser traduzido em números. A interpretação dos fenômenos e a atribuição de significados são básicas no processo de pesquisa qualitativa. Não requer o uso de métodos e técnicas estatísticas. $O$ ambiente natural é a fonte direta para coleta de dados e o pesquisador é o instrumento-chave. É descritiva. Os pesquisadores tendem a analisar seus dados indutivamente. $O$ processo e seu significado são os focos principais de abordagem.

Sob esses fundamentos, buscando contextualizar esta pesquisa quanto ao seu delineamento, podemos dizer que ela é de natureza aplicada, pois o conhecimento gerado visa a aprimorar a atuação docente no contexto da Educação Infantil, considerando as tecnologias digitais. Por isso, para a realização do projeto de aprendizagem que é objeto de estudo desta pesquisa, consideramos a importância de envolver as crianças no processo, visto que elas estão constantemente questionando e levantando hipóteses sobre o ambiente à sua volta, sobre fatos e acontecimentos que despertam sua curiosidade - afinal,

\begin{abstract}
Desde pequenas, as crianças observam o mundo e formulam perguntas acerca dele, com a intenção de entendê-lo. Pela experiência e pela interação com os objetos, fatos e pessoas, elas vão produzindo respostas que, certas ou erradas, não são construídas ao acaso. A experiência pode não ser profunda ou suficientemente extensa, a potencialidade dos seus pensamentos pode ser insuficiente para formular o que nós chamamos de uma teoria científica, mas o processo pelo qual as crianças observam o entorno, formulam perguntas, buscam respostas e desenvolvem seus entendimentos e explicações para o que observam é muito semelhante ao processo de investigação científica. (COSTA, MAGDALENA, 2008, p. 3).
\end{abstract}

Com isso, compreendemos que um projeto de aprendizagem deve partir dos questionamentos das crianças, cuja pesquisa é conduzida a partir das interrogações que elas realizam, as quais conduzem, então, o processo investigação que embasa o projeto. Assim, "é fundamental que a questão a ser pesquisada parta da curiosidade, das dúvidas, das indagações do aluno, ou dos alunos, e não imposta pelo professor. Isto porque a motivação é intrínseca, é própria do indivíduo". (FAGUNDES, 1999, p. 16).

Do ponto de vista de seus objetivos (GIL, 1991), o estudo configura-se como pesquisa exploratória, pois visa a proporcionar maior familiaridade com o problema, com vistas a torná-lo explícito ou a construir hipóteses. Envolve, enquanto procedimentos técnicos, o estudo de caso.

Em geral, os estudos de caso representam a estratégia preferida quando se colocam questões do tipo "como" e "por que", quando o pesquisador tem pouco controle sobre os acontecimentos e quando o foco se encontra em fenômenos contemporâneos inseridos em algum contexto da vida real. (YIN, 2005, p. 19). 
Durante a realização do projeto de aprendizagem, a certeza provisória, por parte das crianças, de que a professora morava na escola deu lugar à dúvida: "onde é a casa da profe?". Além disso, o questionamento de onde era a casa do "cabeludo" possibilitou o levantamento de muitas hipóteses por parte das crianças, a partir das suas experiências e vivências cotidianas. Junto a essas dúvidas, levantou-se o questionamento de onde era a casa de cada criança da turma.

O primeiro esboço que realizamos referente ao projeto de aprendizagem tinha como questão norteadora o seguinte questionamento: "considerando seu amplo acesso a diversas tecnologias junto a suas famílias, o que chama a atenção das crianças no ambiente externo da escola de Educação Infantil?". Diante disso, reconhecemos as seguintes certezas provisórias: as crianças possuem amplo acesso a tecnologias digitais como jogos e vídeos, acessados através do uso de aparelhos de celular; elas precisam vivenciar momentos em contato com a natureza; e o pátio seria um espaço que também poderia despertar a curiosidade e promover o conhecimento. Nossas dúvidas temporárias, nesse primeiro esboço do projeto de aprendizagem, tinham o objetivo de descobrir: quanto tempo as crianças passavam, em casa, em frente a televisão ou com o celular na mão? O que elas acessavam nos celulares? Será que as crianças construíam conhecimento fora da sala de aula em momentos livres na pracinha? Qualquer espaço externo possibilita momentos de descobertas para elas? E como o pátio poderia ser uma ferramenta de promoção do conhecimento? Dessa forma, esse primeiro esboço do projeto de aprendizagem tinha como objetivo analisar se as crianças construíam conhecimento fora da sala de aula em momentos livres na pracinha; o que chamava a atenção delas no ambiente externo da escola de Educação Infantil; e como o pátio poderia ser uma ferramenta de promoção de conhecimento. Porém, provocados pelas intervenções do professor da Atividade Acadêmica na qual foi concebido o projeto, como grupo, reavaliamos tudo aquilo que tínhamos pensado e escrito até então, e refizemos a proposta do projeto de aprendizagem.

Primeiramente, retomamos nossas dúvidas temporárias, repensando como o pátio poderia ser uma ferramenta de promoção do conhecimento. Observando as interações das crianças, percebemos que elas costumavam observar e questionar fatos e acontecimentos do cotidiano; e que o pátio era um espaço que também poderia despertar a curiosidade e promover 0 conhecimento, mas que não poderíamos permanecer apenas naquilo que ele poderia oferecer, considerando que a Educação Infantil tem por objetivo a ampliação do universo de experiências, conhecimentos e habilidades das crianças, a fim de diversificar e consolidar novas aprendizagens. Assim, através das brincadeiras e interações, as crianças estabelecem relações, levantam hipóteses, criam argumentos, questionam fatos e acontecimentos e constroem significados sobre si, os outros e o mundo.

Com novos olhares e reflexões, a questão norteadora partiu então do questionamento das crianças. A questão levantada por elas, "onde é a casinha dele?", surgiu a partir de um momento de brincadeira no pátio da escola, quando, ao brincarem perto de um tronco de árvore, perceberam que ali havia um "cabeludo" (taturana), parando o que estavam fazendo para observá-lo. Logo, mais crianças também se aproximaram para observar. Durante o tempo em que permaneceram assistindo ao "cabeludo", as crianças conversavam sobre o possível local para 
onde ele estaria indo, e chegaram à conclusão de que o animal estava se dirigindo à sua "casinha". Diante dessa hipótese, queriam, então, saber: "onde era a casinha dele?". Dessa forma, o desenvolvimento do projeto iniciou a partir do questionamento de onde era a casa do cabeludo (taturana), seguido do questionamento sobre onde era a casa da professora (visto que as crianças imaginavam que ela morava na escola) e onde era a casa de cada criança da turma.

Buscando pesquisar sobre as dúvidas levantadas, foram utilizados diferentes meios como: vídeos disponíveis na internet sobre a vida das taturanas; convite às famílias para enviar para a escola uma foto da casa onde cada criança morava; assim como diferentes ferramentas, que foram utilizadas com o objetivo de ampliar o repertório das crianças referente ao uso das tecnologias digitais. Para isso, utilizamos o Google Maps, através do qual buscamos a localização da casa de cada criança, da casa da professora e da escola; e o Google Street View, através do qual "passeamos" pelo entorno da escola e da casa de algumas crianças. Porém, como aponta Fagundes, "Buscar a informação em si, não basta. É apenas parte do processo para desenvolver um aspecto dos talentos necessários ao cidadão. Os alunos precisam estabelecer relações entre as informações e gerar conhecimento". (FAGUNDES, 1999, p. 23).

Portanto, além do contato com diferentes materiais e matérias, esse projeto de aprendizagem considerou a realidade na qual a escola está inserida, buscando também possibilitar às crianças o contato com diferentes ferramentas e tecnologias digitais, assim como envolver as famílias no processo de investigação. As etapas da pesquisa serão detalhadas na seção 5 .

\section{Contexto e participantes da pesquisa}

O projeto de aprendizagem "Onde é a casinha dele?" foi realizado em uma escola pública da rede municipal de ensino, no Bairro Santo Afonso, em Novo Hamburgo - RS, com uma turma de Faixa Etária 3 do turno da tarde. O grupo é composto por quinze crianças, sendo nove meninas e seis meninos, com idades entre três e quatro anos. Das crianças que fazem parte da turma, apenas uma já frequentava a escola no ano anterior. Todas as demais passaram a frequentar a escola no ano de 2018, e nenhuma delas não frequentava escola alguma no ano anterior.

A escola fica localizada num bairro de periferia e atende a crianças da Faixa Etária 1 até a Faixa Etária 4, funcionando em turno integral (para as FE 1, 2 e 3). Tem atendimento no turno da manhã para a turma da Faixa Etária 4 e à tarde para a segunda turma da Faixa Etária 3, na qual este projeto foi realizado. A organização das turmas por faixa etária segue as orientações da Secretaria Municipal de Educação.

Quando a então Creche foi inaugurada, no auge da produção do calçado em Novo Hamburgo, os moradores do bairro eram, em sua maioria, famílias vindas do interior do Estado em busca de oportunidades de emprego, principalmente nas indústrias de calçados e artefatos. Com o tempo, tendo em vista a queda da economia calçadista na cidade, um grande número de empresas fechou suas portas; assim, pais e mães de família ficaram desempregados, e muitas crianças e adolescentes começaram a ajudar no sustento coletando material para reciclagem - outra atividade frequente dos moradores da região. Além disso, muitas famílias retornaram para seus locais de origem. A economia do bairro restringiu-se a algumas poucas empresas, comércio e 
atividades informais. Havia falta de saneamento básico e moradias inadequadas. O bairro possuía poucas atividades de lazer para a população - algumas entidades ofereciam atividades para crianças e adolescentes no contraturno, mas a demanda sempre foi grande, e a oferta, escassa.

Essa situação se prolonga até os dias de hoje. O desemprego aumentou consideravelmente o número de trabalhadores informais (dado este revelado no momento de inscrições e matrículas na Escola). Há falta de estrutura, com arroios a céu aberto, lixo e grande número de cachorros pelas ruas; precariedade dos serviços de saúde, considerando que os postos possuem atendimento limitado; e falta de segurança, conforme apontado na Pesquisa Socioantropológica (PSA) de 2009 por $38 \%$ dos entrevistados, que consideraram isso uma grande preocupação da comunidade. Parte desse problema foi minimizado com a implantação do Projeto de Patrulha Escolar, em que uma viatura da Guarda Municipal faz ronda nas escolas da região, porém deixando a desejar nos horários de abertura e fechamento da instituição. A quantidade de escolas também mostra-se aquém do necessário, em especial no atendimento às crianças bem pequenas (creche e pré-escola). Em contrapartida, as instituições existentes destacam-se pela organização, pelo tratamento igualitário e pela qualidade de ensino/aprendizagem (conforme apontado por $24 \%$ dos entrevistados nessa mesma PSA).

De acordo com a filosofia da escola, o planejamento não privilegia só o saber conhecer, mas o saber fazer, o saber ser e, principalmente, o saber conviver, pois entende que a criança pequena aprende a partir de seus interesses, de sua vontade de pesquisar e dos desafios que encontra. Por isso, o trabalho na escola precisa estar pautado na intencionalidade pedagógica, através de ações que garantam as condições para a realização das mais variadas experiências. Nesse sentido, acreditamos que um currículo pautado na valorização da infância promove um planejamento mais eficaz, tendo em vista que são as próprias crianças que participam do processo de construção de conhecimentos, mediados pelo professor.

O projeto de aprendizagem desenvolvido neste contexto, de março a junho de 2018, foi realizado por um grupo de alunas que estavam cursando a graduação em Pedagogia na Unisinos, por meio do projeto PARFOR, o qual tem como pré-requisito o vínculo com uma escola pública. Por isso, o projeto foi desenvolvido na escola de uma das alunas.

\section{Projeto de aprendizagem: etapas, dados, análises e reflexões}

O processo de análise dos dados e de escrita dos resultados consiste em: retomar o foco principal da pesquisa e, tendo em mente a teoria, olhar para os dados produzidos, a fim de compreendê-los. Seguindo a proposta de uma análise qualitativa, os dados foram então organizados de acordo com as etapas do projeto de aprendizagem.

\subsection{0 início das investigações}

Dando início à realização do projeto, em uma tarde, o vídeo em que as crianças aparecem observando o "cabeludo" (Figura 1) e questionando onde é a sua casa foi apresentado para a turma, por meio do uso de um notebook. Em um momento de conversa, as crianças foram 
questionadas sobre onde era a casa do "cabeludo", surgindo as seguintes hipóteses: "Ele mora lá na árvore"; "Ele mora lá na flor da minha Mãe". Após o diálogo e o levantamento das hipóteses, foram apresentadas algumas imagens de taturanas na natureza, e a turma assistiu a um vídeo disponível na internet sobre o assunto. Quanto a esse aspecto, segundo Fagundes, Sato e Maçada (1999, p. 16), "É fundamental que a questão a ser pesquisada parta da curiosidade, das dúvidas, das indagações do aluno, ou dos alunos, e não imposta pelo professor. Isto porque a motivação é intrínseca, é própria do indivíduo."

A partir disso, as crianças foram convidadas a fazer a casa do "cabeludo", utilizando argila e o que mais desejassem coletar pelo pátio da escola.

Figura 1 - Construção da casa com argila

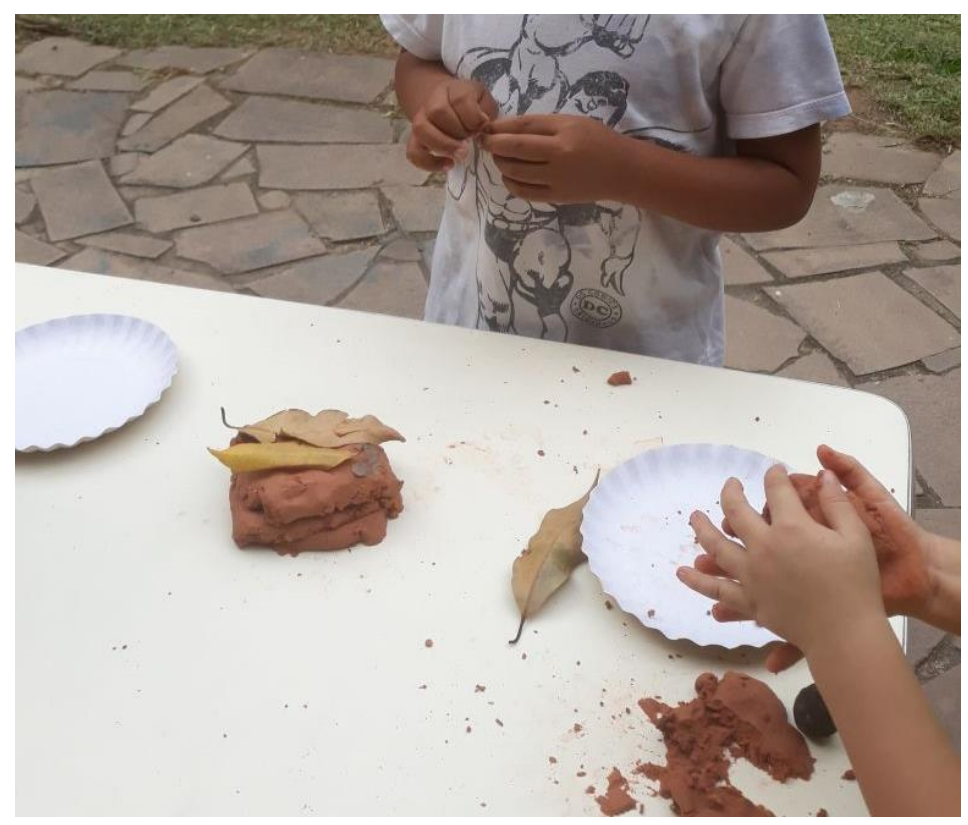

Fonte: Registrada pelos autores.

Essa atividade foi realizada considerando a importância de as crianças manusearem materiais que possibilitassem o contato com diferentes texturas, pois "Cada material propicia uma série de descobertas para a criança. A matéria tem uma mensagem sensorial, como textura, peso, transparência, maleabilidade, densidade, elasticidade". (Redin, 2014, p. 7). Por isso, é importante promovermos o contato com diferentes materiais no contexto da Educação Infantil. 
Figura 2 - Observando o "cabeludo"

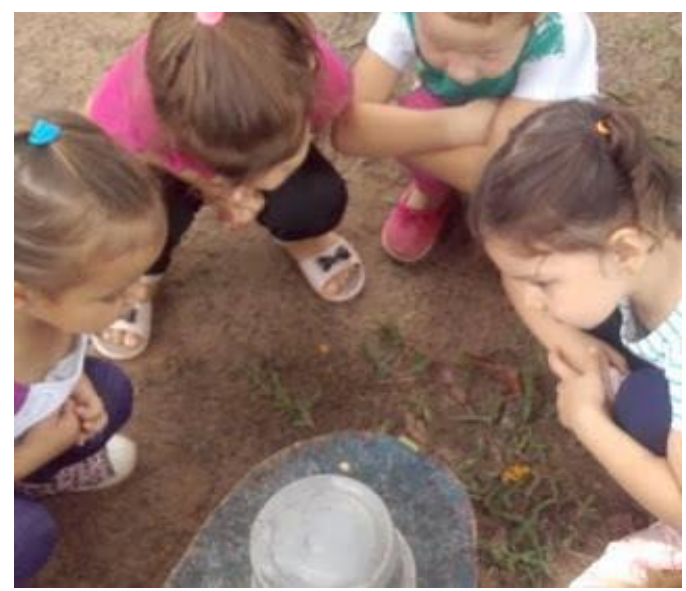

Fonte: Registrada pelos autores.

Nesse processo de construção, utlizando diferentes recursos, as crianças materializaram as descobertas, desenvolveram a criatividade e foram sentindo o mundo que as cercava, à sua maneira. Esse processo foi importante, pois elas foram confrontando o seu pensamento com os diferentes recursos a elas disponibilizados.

\subsection{As fotos das casas e a construção com blocos de madeira}

Num segundo momento, solicitamos que as famílias enviassem para a professora, pelo WhatsApp, uma foto da casa em que cada criança morava. Essa atividade tinha como objetivo envolver as famílias no processo, considerando que somente os pais possuíam os dispositivos tecnológicos necessários para o envio das imagens. Em seguida, as fotos foram impressas e colocadas numa parede da sala (Figura 3). Logo que as viram, as crianças foram até o local em que as fotografias haviam sido colocadas e, com expressões de alegria e surpresa, mostravam para os colegas qual era a sua casa, identificando, então, o local onde moravam.

Figura 3 - Fotos das casas

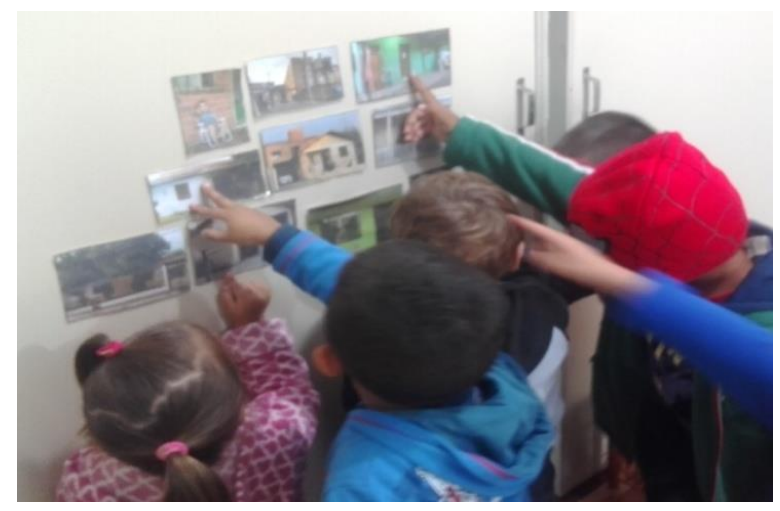

Fonte: Registrada pelos autores. 
Utilizando os blocos de madeira, as crianças foram convidadas a construírem a sua casa. A atividade foi recebida com bastante entusiasmo; e cada uma delas, ao construir sua própria casa (Figura 3), chamava a professora para compartilhar aquilo que havia construído. O objetivo dessa etapa era que pais e filhos pudessem construir uma casa juntos, considerando que

\begin{abstract}
Os blocos de construção tornam o prazer de construir acessível a todas as idades. A madeira tem uma mensagem diferente e especial, pois remete as crianças aos 'materiais verdadeiros'. A madeira possui diversas mensagens sensórias, como textura, peso, forma, calor densidade. A tridimensionalidade dos blocos de madeira propicia uma série de descobertas. (REDIN, 2014, p. 38).
\end{abstract}

Dessa forma, a escolha pelos blocos de madeira também considerou a importância de, na Educação Infantil, as crianças manusearem materiais que possibilitem o contato com diferentes texturas, conforme citado anteriormente. Além disso, conforme Redin (2014), os blocos de madeira proporcionam uma experiência verdadeira ao serem manipulados.

Figura 4 - Construções utilizando blocos de madeira

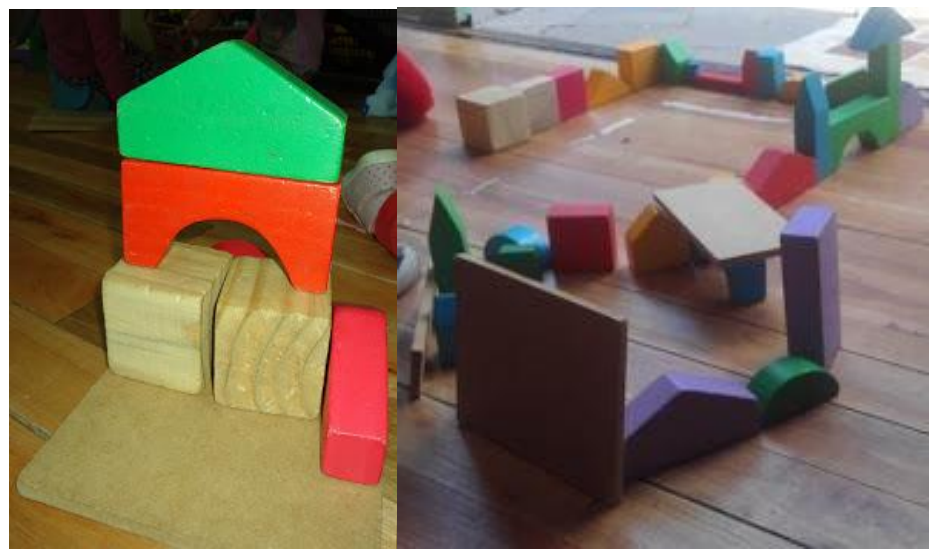

Fonte: Registrada pelos autores.

Importante notar as interações desencadeadas presentes no projeto: entre escola e as famílias; entre as crianças; e entre o uso do analógico e do digital. Na perspectiva construtivista, a interação é um elemento essencial - e não somente entre professor e aluno, mas também na relação com o meio:

[...] a presença do professor reveste-se de enorme importância, mas sua ação não se esgota nele mesmo; ela se prolonga nas ações dos alunos. Por que o professor age assim? Porque ele acredita, ou, melhor, compreende (teoria), que o aluno só aprenderá alguma coisa, isto é, construirá algum conhecimento novo, se ele agir e problematizar a própria ação, apropriar-se dela e de seus mecanismos íntimos. (BECKER, 1994, p. 21).

É nessa epistemologia que todos os atores são ativos no processo; e, com isso, o hibridismo pode ser pensado como disparador da problematização para a construção do conhecimento. Segundo Becker (1994), professor e aluno determinam-se mutuamente, mediados pelos 
conteúdos e também pelas tecnologias digitais, as quais proporcionam uma interação, superando os limites de tempo e de espaço impostos pela educação presencial física.

\subsection{Google Maps e Google Street View: possibilidades de transcender o espaço da escola}

Um mapa ampliado (Figura 5), com marcações da localização das casas de cada criança da turma, da casa da professora e da escola ficou ao alcance das crianças, despertando interesse e curiosidade em descobrir onde ficavam a escola, a sua casa e a da professora. Após a apresentação do mapa para as crianças e a indicação das localizações, por um período de dois meses, espontaneamente, duas ou mais crianças se juntavam em frente ao mapa para conversar e mostrar a localização da sua casa, da escola, da casa da professora e da dos colegas. Como recurso, utilizou-se a imagem impressa gerada pelo Google Maps, com as localizações das casas e da escola.

Figura 5 - Localizações no Google Maps

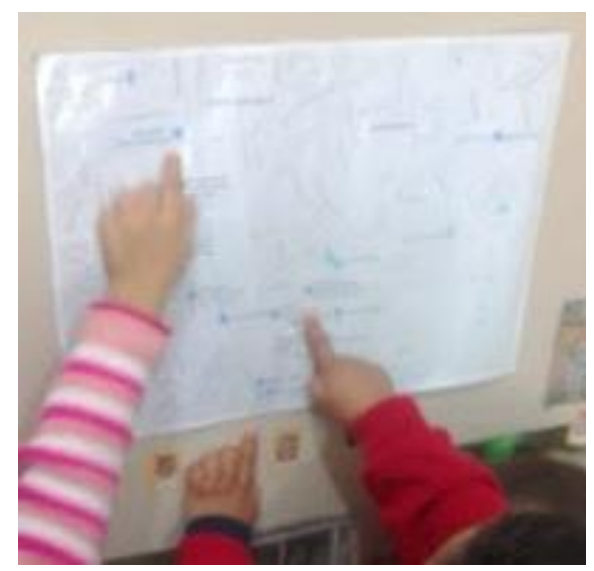

Fonte: Registrada pelos autores.

Num outro momento, utilizando o projetor de imagens e o aplicativo Google Maps, localizamos a escola, a casa de cada criança e a da professora. Pelo Google Street View, visitamos cada uma dessas localidades, passeando pelas ruas próximas à instituição. Duas crianças que moravam em ruas próximas à escola indicaram como chegar até a sua casa apenas olhando a projeção da imagem e orientando a professora, por meio da tecnologia (Figura 6): 
Figura 6 - Transcendendo o espaço da escola com o Google Street View

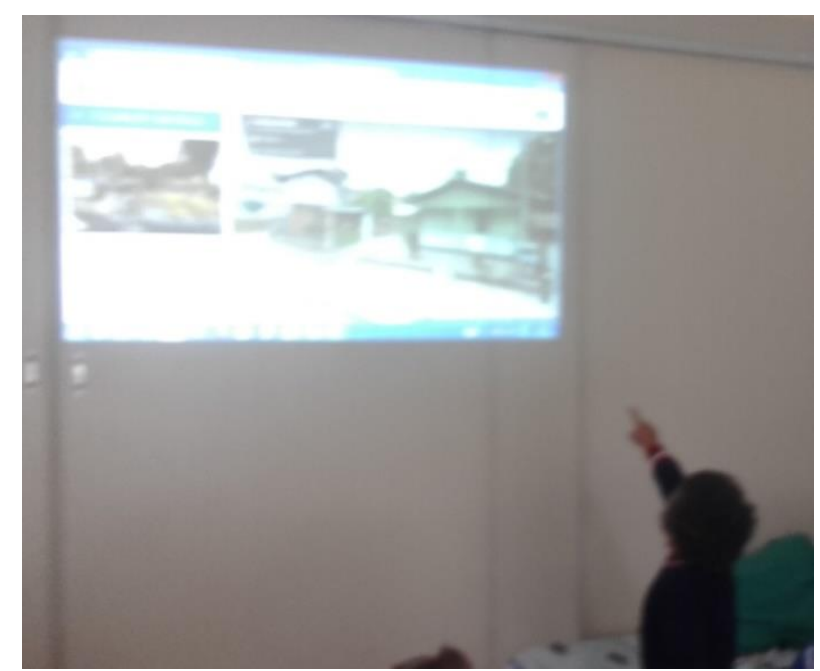

Fonte: Registrada pelos autores.

\subsection{Ligando imagens e localização no Google Maps}

Para que as crianças pudessem mais facilmente associar a localização de cada casa e da escola, na imagem impressa do Google Maps, com a respectiva criança e a professora, ligamos as fotos das casas com a localização no mapa, utilizando um fitilho. Ao analisarem as ligações realizadas, algumas crianças criaram suas hipóteses em relação à localização da sua casa e à localização da casa de alguns colegas, como: "A minha casa fica embaixo da casa da Isadora" (aluno Thales) e "A minha casa é perto da casa da Valentina" (aluna Vitória).

Figura 7 - Casas e escola ligadas à localização no Google Maps

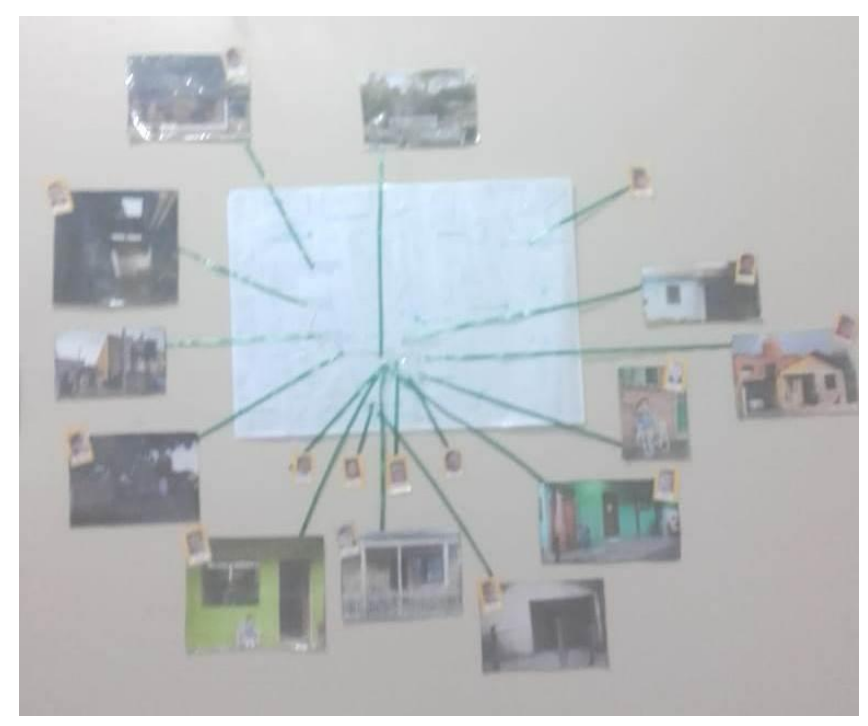

Fonte: Registrada pelos autores.

Encerrando o projeto, em que pesquisamos a localização da casa de cada criança, da casa da professora e da escola, as crianças socializaram aquilo que descobriram desde a pergunta inicial 
- "onde é a casinha dele?" - com pessoas que visitaram a sala de referência da turma. Tais descobertas foram compartilhadas através do blog Pequenos Descobridores.

\title{
6 Considerações finais
}

A realização deste projeto de aprendizagem - cuja questão norteadora inicial era: "considerando o amplo acesso das crianças a diversas tecnologias junto a suas famílias, o que chama a sua atenção no ambiente externo da escola de Educação Infantil?" - proporcionou grandes deslocamentos na nossa maneira de pensar esse nível educacional no contexto da tecnologia. Além disso, contribuiu para que repensássemos nossas práticas docentes, especialmente no que diz respeito ao uso das tecnologias digitais, tendo em vista o quanto estas nos possibilitaram a realização de um projeto que tivesse a criança como protagonista, como aquela que, a partir dos seus questionamentos, foi direcionando o nosso fazer pedagógico e o processo de ensino e aprendizagem.

Com isso, o projeto possibilitou, conforme Di Felice (2012b), uma imersão que, baseada num ecossistema, estabeleceu uma interação constante e contínua entre professores, alunos, famílias, tecnologias e o bairro onde vivem. Conforme o autor,

Não podemos mais pensar as mídias como "ferramentas", instrumentos a serem utilizados, pois, ao utilizarmos novos meios, passamos a desenvolver novos tipos de interação e experimentamos novas formas de interação social. Desde as redes sociais digitais (social network) aos celulares, as tecnologias midiáticas são

portadoras de inovação não apenas no âmbito tecnológico, comunicativo e sensorial, mas também no âmbito mais amplo do social, alcançando seus diversos níveis, político, econômico, organizativo, cultural, etc. (DI FELICE, 2012a).

Com a elaboração do projeto de aprendizagem, estabeleceu-se o social reticular, que tem como fundamento a cultura ecossistêmica, alinhando ação e conhecimento do sujeito:

\begin{abstract}
O social reticular é expressão de uma cultura ecossistêmica nos contextos digitais dos processos comunicativos e que caracteriza as formas de uma inteligência relacional, sem centro e distribuída em todos os lugares. A ação e o conhecimento do sujeito se tornam assim relacionados e não mais autocentrados, resultado de uma qualidade conectiva que manifesta a passagem da comunicação com o ambiente à comunicação no ambiente. (DI FELICE, 2012a).
\end{abstract}

Sendo assim, há para os alunos a "possibilidade de não serem apenas receptores de informação, mas também produtores, os indivíduos conectados em rede podem ultrapassar a tradicional e hierárquica dicotomia emissor-receptor". (DI FELICE, 2012b, p. 52).

Acreditamos que a falta de interação, de uma escuta atenta do professor para os questionamentos das crianças, de um olhar que promova possibilidades de descobertas, impede que a criança construa conhecimentos e seja protagonista no processo de ensino e aprendizagem. Considerando tal aspecto, a partir da realização deste projeto, tivemos a oportunidade de aprender o quanto as tecnologias digitais podem contribuir para o processo de ensino e aprendizagem, sem que sejam utilizadas apenas como um meio de pesquisa, mas como uma 
ferramenta que contribui para a promoção do conhecimento e a ampliação do repertório tanto das crianças como de nós, professores. Importante destacar também que, como as crianças não possuíam dispositivos tecnológicos, a articulação do projeto com as famílias foi extremamente importante para o seu desenvolvimento. Cabe ressaltar ainda que o hibridismo entre o analógico e o digital proporcionaram um bom desenvolvimento do projeto, pois não se tratava de priorizar um ou outro meio, mas sim de primar pela articulação entre diferentes experiências que proporcionaram as aprendizagens.

\section{Referências}

ALMEIDA, M. E. B. Tecnologia na escola: criação de redes de conhecimentos. In: ALMEIDA, M. E. B.; MORAN, J. M. (Org.). Integração das Tecnologias na Educação: salto para o futuro. Brasília: Ministério da Educação, p. 70-73, 2005. Disponível em:

<http://portal. mec.gov.br/seed/index.php?option=content\&task=view\&id=165\&Itemid=303>. Acesso em 052018.

BECKER, F. Modelos pedagógicos e modelos epistemológicos. Educação e Realidade, Porto Alegre, v. 19, n.1, p. 89-96, 1994.

BRASIL Conselho Nacional de Educação; Câmara de Educação Básica. Resolução nº 5, de 17 de dezembro de 2009. Fixa as Diretrizes Curriculares Nacionais para a Educação Infantil. Diário Oficial da União, Brasília, 18 de dezembro de 2009, Seção 1, p. 18. Disponível em:

<http://portal.mec.gov.br/index.php?option=com_docman\&view=download\&alias=2298-rceb005-

09\&category_slug=dezembro-2009-pdf\&Itemid=30192>. Acesso em: 16 abr. 2018.

BRASIL. Ministério de Educação e Cultura. Base Nacional Comum Curricular. Brasília, 2017. Disponível em <http://basenacionalcomum.mec.gov.br/>. Acesso em: 16 abr. 2018.

CHARLOT, B. A Pesquisa educacional entre conhecimentos, políticas e práticas: especificidades e desafios de uma área de saber. Revista Brasileira de Educação, Rio de Janeiro, v. 11, n. 31, p.7-18, jan./abr. 2006.

COSTA, I. E. T.; MAGDALENA, B. C. Revisitando os Projetos de Aprendizagem, em tempos de web 2.0. In: SIMPÓSIO BRASILEIRO DE INFORMÁTICA NA EDUCAÇÃO, 12., 2008, Fortaleza. Anais... Fortaleza: SBIE, 2008.

DRESCH, A.; LACERDA, D. P.; ANTUNES, J. Design science research: método de pesquisa para o avanço da ciência e tecnologia. Porto Alegre: Bookman, 2015.

DI FELICE, M. Redes Sociais Digitais, epistemologias reticulares e a crise do antropomorfismo social. Revista USP, São Paulo, v. 22, p. 06-19, 2012a.

DI FELICE, M.; TORRES, J. C.; YANAZE, L. K. H. Redes digitais e sustentabilidade - as interações com o meio ambiente na era da informação. 1. ed. São Paulo: Annablume, 2012b. v. 1.

FAGUNDES, L. C.; SATO, L. S.; MAÇADA, D. L. Projeto? O que é? Como se faz? In: FAGUNDES, L. C.; SATO, L. S.; MAÇADA, D. L. (Orgs.). Aprendizes do Futuro: as inovações começaram! Brasília: MEC, 1999. Disponível em: <http://mathematikos.psico.ufrgs.br/textos.html>. Acesso em: 06 abr. 2018.

GIL, A. C. Como elaborar projetos de pesquisa. São Paulo: Atlas, 1991.

GODOY, A. S. Pesquisa qualitativa: tipos fundamentais. Revista de Administração de Empresas, São Paulo, v. 35, n. 3, p. 20-29, maio/jun. 1995.

LATOUR, B. Jamais fomos modernos: ensaio de antropologia simétrica. 3. ed. Rio de Janeiro: Ed. 34, 2013. 
LEMOS, A. O que é Cibercultura. [S. I.: s. n.], 30 nov. 2010. 1 vídeo (5 min 54 s). Disponível em: <https://www.youtube.com/watch?v=hCFXsKeIs0w>. Acesso em: 23 maio 2016.

LINCOLN, Y. S.; GUBA, E. G. Paradigmatic Controversies, Contradictions and Emerging Confluences. In: DENZIN, N.; LINCOLN, Y. S. (Orgs.) Handbook of Qualitative Research. Thousand Oaks: Sage, p. 163-188, 2000.

MINAYO, M. C. S. O desafio da pesquisa social. In: MINAYO, M. C. S. (Org.). Pesquisa Social: teoria, método e criatividade. 26. ed. Petrópolis, RJ: Vozes, p. 9-29, 2007.

REDIN, M. M. Desenhar - muito mais do que uma experiência gráfica. In: FOCHI, P. S.; REDIN, M. M. Infância e Educação Infantil II: linguagens. São Leopoldo-RS: Unisinos, 2014.

SANTANA, A. P. Teoria Ator-Rede: uma alternativa para pensar a Comunicação em contextos digitais. In: CONGRESSO BRASILEIRO DE CIÊNCIAS DA COMUNICAÇÃO - INTERCOM RIO 28., 2015, Rio de Janeiro. Anais... Rio de Janeiro: Intercom, 2015.

SCHLEMMER, E. O Trabalho do Professor e as Novas Tecnologias. Textual, Porto Alegre, v. 1, n. 8, p. 3342, 2006. Disponível em:<http://www.sinprors.org.br/textual/set06/artigo_tecnologia.pdf>. Acesso em: 22 abr. 2018.

SCHLEMMER, E. Mídia social em contexto de hibridismo e multimodalidade: o percurso da experiência na formação de mestres e doutores. Revista Diálogo Educacional, Curitiba, v. 45, p. 399-421, 01 set. 2015.

SILVA, E. L.; MENEZES, E. M. Metodologia da pesquisa e elaboração de dissertação. 3. ed. Florianópolis: Laboratório de Ensino a Distância da UFSC, 2001.

YIN, R. K. Estudo de caso: planejamento e métodos. 3. ed. Porto Alegre: Bookman, 2005.

Recebido em novembro de 2018.

Aprovado para publicação em setembro em 2019. 